\title{
Some Results from Sixteen Years of Leprosy Control Work in the Khon Kaen Province of N.E. Thailand
}

\author{
ANAN C. PAKDI \\ Leprosy Control Division, Department of Health, Thailand \\ CHAIYAN K. SANAYAKORN \\ Department of Biostatistics, Faculty of Public Health, Mahidol University \\ and \\ K. S. SEAL \\ World Health Organization
}

\begin{abstract}
The changes in the epidemiological situation of leprosy in the Province of Khon Kaen in N. E. Thailand are assessed from the results of two comparable stratified leprosy surveys conducted at an interval of 10 years. A marked decline in the overall prevalence of the disease is demonstrated despite the persistence of a large reservoir of unregistered cases. It is considered that intensification of certain operational and investigatory measures could reduce further the transmission of the disease.
\end{abstract}

\section{Introduction}

The Khon Kaen Province is one of the largest and most important of the 15 provinces comprising the North Eastern Region of Thailand. This Region, which is a low plateau bounded on its northern and eastern flanks by the Mekong River, has been recognized since the early 1950s as being highly endemic for leprosy. Because of its strategic position in the Region and its available institutional facilities, Khon Kaen Province was chosen in 1956 as the pilot area for a leprosy control project, initiated by Government in association with the World Health Organization and the United Nations Children's Fund (Fig. 1).

Within 5 years of the establishment of treatment services and case-finding procedures, which included the examination of all case contacts and selective village surveys, the registration of patients exceeded 9000 in a population of 700,000 , although some $20 \%$ of the patients were in fact, not strictly within the bounds of the province, having been attracted there by the prospect of treatment. Considerable reliance was placed on the provision of services through mobile treatment units, although static centres were established at some of the Government rural health units, at that time very limited in number.

\section{First Survey}

In 1962, 6 years after the inception of the project the WHO Headquarters Leprosy Advisory Team (L.A.T.) conducted a stratified random sampling survey

Received for publication 23 May, 1974. 


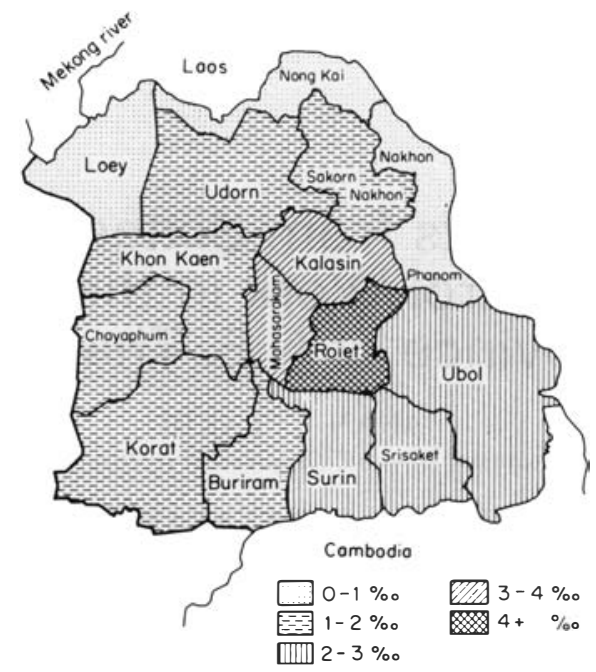

Fig. 1. North-eastern Thailand leprosy rate per 1000 by registered cases 1972 -showing position of Khon Kaen Province.

to assess the epidemiological situation and to evaluate certain aspects of the project operations. The provincial population of 720,000 was stratified by its nine districts or blocks, and 16,860 persons in 33 sampling units were screened.

The results showed an overall point prevalence rate of 12.37 per thousand and a lepromatous rate of 4.58 . The prevalence rates in the districts varied widely from 3.4 to 22.79 per thousand. The conclusion was reached, that in addition to the 6100 patients resident in the province and receiving treatment, there were probably 2800 undetected cases, that is $31 \%$ of the total estimated cases.

Almost 3 years later, two important events occurred which changed the conduct of the work in the province. Firstly, a special campaign was mounted for medical officers to make a thorough clinical review of all the registered patients, to establish more accurate clinical data, and to release from control the inactive cases who fulfilled the criteria for release currently recommended by the WHO Expert Committee on Leprosy. Thus by the end of 1965 the registered cases had been reduced to 3200 . Secondly, and concurrently with the review, there was a reorganization of the field operations entailing the abandonment of mobile teams and the establishment of additional static centres, and of particular importance, associated subcentres, to bring the leprosy services as close as possible to the village patients.

The reduction of the case load and the provision of subcentres effected two vital improvements in the efficiency of the control organization.

(a) There was a progressive improvement in the attendance regularity of patients for treatment, so that by 1968 the overall figure of patients having treatment regularly (i.e. $75 \%$ of possible treatments) was $72 \%$ and that for lepromatous cases $78 \%$ (Table 1).

(b) A reasonably adequate surveillance was being exercised on the contacts of all forms of leprosy from 1966 (Table 2). 
TABLE 1

A nnual rates of regular treatment for period 1965-71

by form and overall rates (annual reports)

\begin{tabular}{|c|c|c|c|c|c|c|c|c|c|}
\hline \multirow{2}{*}{ Year } & \multicolumn{3}{|c|}{$\mathrm{I}$ and $\mathrm{T}$} & \multicolumn{3}{|c|}{$\mathrm{L}$} & \multicolumn{3}{|c|}{ Total I-L-T } \\
\hline & $\begin{array}{c}\text { Total } \\
\text { patients }\end{array}$ & Regular & $\%$ & $\begin{array}{c}\text { Total } \\
\text { no. }\end{array}$ & Regular & $\%$ & $\begin{array}{c}\text { Total } \\
\text { no. }\end{array}$ & Regular & $\%$ \\
\hline 1967 & 929 & 440 & 47 & 1269 & 755 & 70 & 2198 & 1195 & 54 \\
\hline 1968 & 965 & 627 & 65 & 1247 & 973 & 78 & 2212 & 1600 & 72 \\
\hline 1969 & 827 & 563 & 68 & 1137 & 848 & 75 & 1964 & 1411 & 72 \\
\hline 1970 & 831 & 599 & 72 & 1087 & 846 & 78 & 1918 & 1445 & 75 \\
\hline 1971 & 43 & 32 & 74 & 1011 & 812 & 80 & 1745 & 1360 & 78 \\
\hline
\end{tabular}

Regular patients are those receiving $75 \%$ or more of the treatments.

TABLE 2

Proportions of contacts examined and attack rate annually, all forms

\begin{tabular}{|c|c|c|c|c|c|c|c|c|}
\hline \multirow{3}{*}{ Year } & \multicolumn{8}{|c|}{ All forms } \\
\hline & \multirow{2}{*}{ Registered } & \multirow{2}{*}{ Examined } & \multirow{2}{*}{$\%$} & \multicolumn{4}{|c|}{ Cases found } & \multirow{2}{*}{ Per mille } \\
\hline & & & & I & $\mathrm{L}$ & $\mathrm{T}$ & Total & \\
\hline 1966 & 5925 & 4484 & 76 & $?$ & $?$ & $?$ & 29 & 6.4 \\
\hline 1967 & 8333 & 4665 & 56 & 6 & 4 & 5 & 15 & 3.2 \\
\hline 1968 & 8993 & 6495 & 72 & - & 3 & 10 & 13 & 2.0 \\
\hline 1969 & 8225 & 6507 & 79 & 2 & 5 & 1 & 8 & 1.2 \\
\hline 1970 & 7842 & 5634 & 71 & 2 & 1 & 4 & 7 & 1.2 \\
\hline 1971 & 7116 & 5630 & 75 & 4 & 1 & 2 & 7 & 1.3 \\
\hline
\end{tabular}

\section{Second Survey}

The second survey of the province was undertaken in 1972 by the authors. The statistical plan adopted was in every way comparable to the earlier survey, using the same frame of blocks, but introducing a substratum by defining all the units for sampling as villages with or without known leprosy cases. A total of 24,010 persons were screened from 44 sampling units, an approximately $2.3 \%$ sample and a $98 \%$ coverage of the same population was obtained.

During the interval between the two surveys the population had grown to more than a million. The results of the survey revealed a reduction in the overall prevalence from 12.37 to 3.75 per thousand, the rate for registered patients being now 2.0 and the unregistered patients 1.75 per thousand. This latter rate for unregistered patients suggested that there might be as many as 1840 patients in the province needing to be brought under treatment.

The nature of the cases found on survey are set out in Table 3. Of the unregistered cases found in the sample, nine were lepromatous (L) or borderline (B) and of these one lepromatous case had relapsed after release and had not sought further treatment, while three others (2L and $1 \mathrm{~B})$ were out of control. 
TABLE 3

Clinical classification of leprosy patients found in sampled units

\begin{tabular}{lccccc}
\hline & Indeterminate & Lepromatous & Borderline & Tuberculoid & Total \\
\hline Registered & - & 29 & - & 19 & 48 \\
Unregistered & 2 & 6 & 3 & 31 & 42 \\
& $(2)$ & $(3)$ & $(2)$ & $(27)$ & $(34)$ \\
Total & 2 & 35 & 3 & 50 & 90 \\
\hline
\end{tabular}

Figures in brackets are new cases.

Hence it was estimated that the number of cases to be detected for the first time could be 1490 out of the total estimated cases for the province of 3290-i.e. $38 \%$ compared with $31 \%$ in 1962.

\section{District Prevalences}

A reduction in prevalence has occurred in each district (Fig. 2). The variation is still wide, from 0.82 to 6.22 per thousand, and the reduction is by no means uniform and appears to be related in part to the ease of communications and access to treatment services.

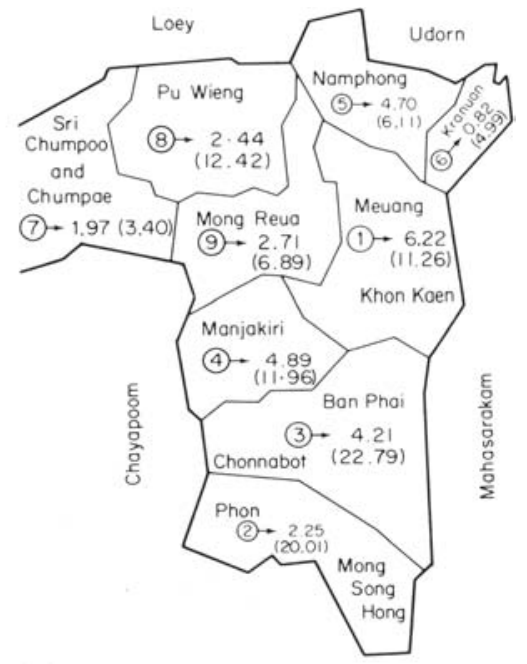

Fig. 2. Khon Kaen Province-showing leprosy rates by block, 1962 and 1972. o, Numbered sampling block; $\rightarrow$, leprosy prevalence (per 1000) in each sample block-1972; figures in brackets, leprosy prevalence-1962.

The Ban Phai and Phon blocks (each now two administrative districts) show the most marked change; Ban Phai from 22.79 (1962) to 4.21 (1972) and Phon 20.01 (1962) to 2.25 (1972). These two districts are traversed by the main north highway, and with the special attention being given by the Government to the 
development of this region, improved communications by feeder roads and the extending of the health and social services has been a feature in the last 10 years. Ban Phai District in particular, with the district capital an important road and rail junction has probably the best coverage with rural health units in the province. Partial integration of the leprosy services into the general health services has already in fact been achieved here. Two of the outlying districts of Sri Chumpoo and Kranuan, which are the least densely populated and had a relatively low endemicity have also shown a steady decline in cases.

The poorer responses in Khon Kaen District and Namphong District are thought to be due to a more fluid population. Khon Kaen Town is virtually the Regional Capital, and there is a steady influx of persons from other provinces seeking employment. Moreover Namphong is the site of a large dam and developing irrigation project which has caused a flow of people to the area, as to Khon Kaen.

\section{Case Detection Rates}

It is not possible to establish the annual incidence rates for the province from survey data, and reliance must be placed on the annual rate of newly registered patients (or case detection rate per 100,000) to give further indications of the trend of the disease. The progressive decline in detection rates, both overall and for lepromatous cases is shown in Table 4 . The field staff in the province has been

TABLE 4

New cases detected and registered annually-1965-71 by age-group and form of leprosy and detection rates per 100,000 population (derived from monthly reports)

\begin{tabular}{|c|c|c|c|c|c|c|c|c|c|}
\hline \multirow{3}{*}{ Year } & \multicolumn{7}{|c|}{ New cases } & \multirow{3}{*}{$\begin{array}{c}\text { Annual } \\
\text { Detection } \\
\text { Rate (ADR) }\end{array}$} & \multirow{3}{*}{$\begin{array}{c}\mathrm{ADR} \\
\mathrm{L} \\
\text { Cases }\end{array}$} \\
\hline & \multicolumn{3}{|c|}{ Adults } & \multicolumn{3}{|c|}{ Children } & \multirow{2}{*}{$\begin{array}{l}\text { Grand } \\
\text { total }\end{array}$} & & \\
\hline & I & $\mathrm{L}$ & $\mathrm{T}$ & 1 & $\mathrm{~L}$ & $\mathrm{~T}$ & & & \\
\hline 1965 & 2 & 58 & 100 & 3 & 4 & 7 & 174 & 19.2 & 6.8 \\
\hline 1966 & - & 67 & 92 & 4 & 3 & 11 & 177 & 18.8 & 7.4 \\
\hline 1967 & 1 & 53 & 83 & 12 & 1 & 14 & 164 & 16.8 & 5.5 \\
\hline 1968 & 1 & 51 & 86 & 3 & 4 & 17 & 162 & 16.0 & 5.4 \\
\hline 1969 & 1 & 30 & 44 & 4 & - & 7 & 86 & 8.2 & 2.9 \\
\hline 1970 & 5 & 24 & 76 & 3 & 1 & 9 & 118 & 10.9 & 2.3 \\
\hline 1971 & 1 & 34 & 47 & 3 & 3 & 3 & 91 & 8.4 & 3.4 \\
\hline
\end{tabular}

reduced from 1970 onwards but the decline in the detection of new cases cannot be attributed to reduced efficiency for supervision from the Regional Headquarters has been good. The relatively poor detection rates among children needs comment. School surveys for leprosy have been the weakest feature of the control organization although routine examinations of school-children are regarded as the normal duty of field staff. In the 1972 survey it is noteworthy that although the age-group $0-14$ years represent some $44 \%$ of the sample population, the number of children found to be suffering from leprosy was only 6 , or $6.7 \%$ of the total number of cases, and none were lepromatous. The overall detection rates show a proportion of lepromatous to the combined indeterminate and tuberculoid cases 
of never less than $1: 3$, except in 1970 when the usual modes of detection were supplemented by a number of village surveys. This exemplifies the general experience that lepromatous cases seek help more readily than do I and T cases. In this present survey the proportion in newly detected cases is almost $1: 7$ because of the proportionately large number of tuberculoid cases who have not sought treatment voluntarily. This suggests that the lepromatous detection rate may indicate trends in incidence more sensitively than the overall detection rate.

\section{Transmission by "Open" Cases}

The 1972 survey revealed that about $76 \%$ of the estimated lepromatous cases are under treatment, and a definite decline in prevalence is proceeding at this level of control.

Three sources of continued transmission were identified by the survey, apart from the appearance of new "open" cases.

(a) Three of the six "out of control" cases seen were lepromatous.

(b) One released lepromatous case had relapsed and had failed to return for further treatment.

(c) Because of the high proportion of lepromatous cases in the sample who have shown persistently positive slit skin smears even after seven years of treatment, an analysis of all case records for the province was undertaken. This revealed that 111 (14\%) out of 777 lepromatous cases who had received treatment for periods ranging from 7 to 13 years were still bacteriologically positive by standard skin smears.

It is considered that a continued reduction in the transmission of the disease and of the disease prevalence level could be achieved by widening the operational measures to include permanent surveillance on all previously released cases, out of control cases and by the investigation in hospital if necessary of persistently positive cases to ascertain the reason for the poor response to treatment, and to take appropriate action.

In the general assessment it was encouraging to find by a review of the case records of all registered cases in the province that $45 \%$ of the indeterminate and tuberculoid patients were clinically inactive, and that $55 \%$ of the lepromatous cases were "inactive" as indicated by negative standard slit skin smears; and thus the epidemiological importance of these patients has been greatly reduced.

In conclusion, the results of the surveys show that the overall point prevalence has declined by $69 \%$ and clearly indicates the valuable effect that the control services are exerting on the endemicity of the disease.

\section{Acknowledgements}

Thanks are due to the Director General, Department of Health, Ministry of Public Health, Thailand, and to the Regional Director, S. E. Asia Region, World Health Organization for permission to publish this abstract from an evaluation report on the Government Leprosy Control Services.

\section{Reference}

World Health Organization (1963). WHO Leprosy Advisory Team, Report on Leprosy Survey in Thailand, unpublished. 